\title{
Photometric and Statistical Analysis of Solar Energetic Particle (SEP) for the Peak of Solar Cycle 24
}

\author{
Wafaa Zaki ${ }^{1}$, Atheer Zidane' ${ }^{1}$ Amjad Al-Sawad ${ }^{2}$ \\ ${ }^{1}$ Department of Physics, College of Science, University of Kirkuk, Kirkuk, Iraq \\ ${ }^{2}$ Department of Physics and Astronomy, University of Turku, Turku, Finland \\ Email: hassanf99@yahoo.com
}

Received 17 June 2016; accepted 29 August 2016; published 2 September 2016

Copyright (C) 2016 by authors and Scientific Research Publishing Inc.

This work is licensed under the Creative Commons Attribution International License (CC BY). http://creativecommons.org/licenses/by/4.0/

(c) (i) Open Access

\section{Abstract}

The major solar energetic particle events for the peak of solar cycle (24) for years (2012-2015) are analyzed by using the Energetic and Relativistic Nucleus and Electrons (ERNE) detectors and Large Angle and Spectrometric Coronagraph Experiment (LASCO) on board SOHO. It is found that the number of events which satisfies the required condition was 82 events. LASCO give information about Central Position Angle (CPA), Angular Width (AW), the speed of associated Coronal Mass Ejections (CMEs) and their basic features which cataloged in a data base SOHO/LASCO. The logarithmic intensity-time profile of SEP for the peak of solar cycle (24) was provided by ERNE, and from this profile the injection time, width, speed and onset time were estimated. All results that arise from these photometric analysis were statistically analyzed by using the statistical program SPSS (version 19). It have been concluded that $90 \%$ of these events were halo $\left(360^{\circ}\right) \mathrm{CPA}, 1 \%$ of North West, $4 \%$ South West and $2 \%$ North East and South East, as well as it was found that $39 \%$ gradual events and $29 \%$ impulsive events while $32 \%$ were not clear events, and also the acceleration of the energetic particle is not only in the interplanetary but also in the location of the event. We found from the statistical analysis for these events that the acceleration is inversely proportional to speed and the relationship between them is not relevant and also the speed increase in two regions, from year 2012 and 2014. This confirms that the peak of solar cycle (24) really is double peak. All these investigations were employed as data base for the space agencies to protect the solar wind.

\section{Keywords}

Coronal Mass Ejections CMEs, Solar Wind, Solar Energetic Particles SEPs, SOHO-LASCO-ERNE: Data Base, Solar Cycle (24) 


\section{Introduction}

The investigation of solar activity is a very important part of space physics because of the significant impact on Earth technological systems. The effective part of solar activity is solar storm which in turn consists of three parts namely The Coronal Mass Ejections (CMEs), Flares and The Solar Energetic Particles (SEPs). The output of X-ray and UV-variation are various with solar cycle and all of these are related to the transients released from large amount of energy from Sun [1]. SEPs are one population of near-Earth particles; they have intermediate energies from some $10 \mathrm{keV}$ /nuclei to the $\mathrm{GeV}$ range and occur in events that last from some hour's to a few days and increase above background by many orders of magnitude. Occasionally eruptions are directed toward the Earth change the conditions of near-Earth space in several ways, including a cut in the electricity power in high latitudes on the Earth and damaged of some satellites [2]. There are two types of SEP, "gradual SEP" and "impulsive SEP"; in this investigation the two types of events have been analyzed specially the high speed events for the peak of solar cycle (24) for years (2012-2015). All observations for this study were taken from Large Angle and Spectroscopic Coronagraph (LASCO), which provide the first ever CMEs database to cover a full solar cycle with a single instrument, thus opening investigations to the solar cycle dependence on CME properties [3]. By using the photometric scale observations of LASCO, so there will be able to find the speed of Coronal Mass Ejections (CMEs), angular width (AW) and the Central Position Angle (CPA), as for finding the intensity-time profile, the energy and the shape of the events which can be obtained from ERNE detectors system. LASCO and ERNE are scientific instruments boarded on SOHO [4]. The main objective of this study is to detect and analyze when and where SEPs take place by finding the location of CMEs and find the time of the events as well as find a statistical description to SEP for the peak of solar cycle (24) for years selected by taking high speed events CMEs with velocities > 1000 (km/s) and angular width > 200 (deg).

\section{Observations and Data Handling}

Research activity has been related to the observation of big solar eruptions. In big solar events, before the magnetic storm hits the Earth, SEPs bombard Earth earlier, and may be both (storm and particles) come from the eruption which is called CME. Observed eruptions are associated with different composition and energy spectra. So the investigation of their source is very important to learn SEPs [5]. SOHO which placed into the hole orbit close to lagrangian point L1 carries twelve scientific instruments, LASCO \& ERNE are some of these devices that data were obtained by them for this study. ERNE provide an opportunity to analyze protons and helium nuclei intensity-time profile with high resolution and LASCO give information about acceleration, CPA, and AW, the speed of CME and their basic attributes which cataloged in a data base known as the SOHO/LASCO catalog Figure 1. The logarithmic intensity-time Profile of SEP associated to CME for the peak of solar cycle (24) for years (2012-2015) were provided by ERNE detectors [6]. From this profile the injection time, speed, width, acceleration, CPA and onset time were estimated. The Injection time $\left(T_{\mathrm{inj}}\right)$ representing the time of particles that Injected from the Sun and it gives the acceleration time for the particles [5]:

$$
T_{\text {inj }}=\left(t_{0}-t_{f}\right)+8.3 \mathrm{~min}
$$

Equation (1) gives the observer to set a real time at the detector.

The flight time can be realized by using beta equation, (this cannot be done without finding the ratio velocity of particles to the velocity of light which is called relativistic velocity coefficient $(\beta)$ [7].

$$
\beta=v / c
$$

where $v=$ the speed of particles $=s / t, c=$ the speed of light.

$\left(t_{0}\right)$ onset time is observed by the detectors, $(8.3 \mathrm{~min})$ have been added to represent the time of light to reach the Earth from the Sun, and the flight time $\left(T_{f}\right)$ given by equation (3):

$$
T_{f}=s / \beta c
$$

where $(s)$ is the fixed path length for the particles which equal the distance between the Sun and the detector (=1.2 AU) [8], and $\beta$ equal

$$
\beta=\left[1-(p /(E+p))^{2}\right]^{1 / 2}
$$




\begin{tabular}{|c|c|c|c|c|c|c|c|c|c|c|c|c|}
\hline \multicolumn{13}{|c|}{ SOHO LASCO CME CATALOG } \\
\hline YEAR & \multicolumn{12}{|c|}{ MONTH } \\
\hline 1996 & Jan & Feb & Mar & Apr & May & Jun & $\underline{\mathrm{Jul}}$ & Aug & Sep & $\underline{\text { Oct }}$ & Nov & Dec \\
\hline 1997 & Jan & $\underline{\underline{F e b}}$ & $\underline{\mathrm{Mar}}$ & Apr & May & $\underline{\underline{\text { Jun }}}$ & $\underline{\mathrm{Jul}}$ & Aug & Sep & $\underline{\underline{\text { Oct }}}$ & Nov & $\underline{\underline{\text { Dec }}}$ \\
\hline 1998 & $\underline{\underline{J a n}}$ & $\underline{\mathrm{Feb}}$ & $\overline{\mathrm{Mar}}$ & Apr & May & $\underline{\text { Jun }}$ & Jul & Aug & Sep & $\overline{\text { Oct }}$ & Nov & $\overline{\text { Dec }}$ \\
\hline 1999 & $\overline{\text { Jan }}$ & $\overline{\overline{F e b}}$ & Mar & Apr & May & Jun & Jul & Aug & Sep & $\underline{\mathrm{Oct}}$ & $\overline{\mathrm{Nov}}$ & Dec \\
\hline 2000 & $\underline{\underline{\text { Jan }}}$ & $\underline{\underline{F e b}}$ & $\underline{\underline{\text { Mar }}}$ & $\underline{\text { Apr }}$ & May & Jun & $\underline{\underline{\mathrm{Jul}}}$ & Aug & $\underline{\underline{\text { Sep }}}$ & $\underline{\underline{\mathrm{Oct}}}$ & $\underline{\underline{N}}$ & $\underline{\underline{\text { Dec }}}$ \\
\hline 2001 & $\underline{\underline{J a n}}$ & $\underline{\underline{F e b}}$ & $\underline{\text { Mar }}$ & $\underline{\text { Apr }}$ & May & $\underline{\text { Jun }}$ & $\underline{\text { Jul }}$ & $\underline{\text { Aug }}$ & $\underline{\text { Sep }}$ & $\underline{\text { Oct }}$ & Nov & $\underline{\text { Dec }}$ \\
\hline 2002 & $\underline{\underline{J a n}}$ & Feb & $\underline{\text { Mar }}$ & Apr & May & $\underline{\underline{\text { Jun }}}$ & $\underline{\text { Jul }}$ & Aug & Sep & $\underline{\mathrm{Oct}}$ & Nov & Dec \\
\hline 2003 & $\underline{\text { Jan }}$ & $\underline{\text { Feb }}$ & $\overline{\overline{M a r}}$ & Apr & May & Jun & $\underline{\text { Jul }}$ & Aug & Sep & $\overline{\overline{\text { Oct }}}$ & Nov & $\overline{\overline{\text { Dec }}}$ \\
\hline 2004 & $\underline{\text { Jan }}$ & $\underline{\text { Feb }}$ & Mar & Apr & May & $\underline{\text { Jun }}$ & $\underline{\text { Jul }}$ & $\underline{\text { Aug }}$ & Sep & $\underline{\underline{\text { Oct }}}$ & Nov & $\underline{\text { Dec }}$ \\
\hline 2005 & $\underline{\text { Jan }}$ & $\underline{\text { Feb }}$ & Mar & Apr & May & Jun & Jul & Aug & Sep & $\underline{\mathrm{Oct}}$ & $\underline{\text { Nov }}$ & $\underline{\text { Dec }}$ \\
\hline 2006 & $\underline{\text { Jan }}$ & Feb & $\underline{\text { Mar }}$ & Apr & May & $\underline{\underline{J u n}}$ & $\underline{\mathrm{Jul}}$ & $\underline{\text { Aug }}$ & Sep & $\underline{\text { Oct }}$ & Nov & Dec \\
\hline 2007 & $\underline{\text { Jan }}$ & $\underline{\text { Feb }}$ & Mar & Apr & May & $\underline{\text { Jun }}$ & Jul & $\underline{\text { Aug }}$ & Sep & $\underline{\text { Oct }}$ & $\underline{\mathrm{Nov}}$ & $\underline{\text { Dec }}$ \\
\hline 2008 & $\underline{\underline{J a n}}$ & $\underline{\text { Feb }}$ & Mar & Apr & May & Jun & $\overline{\overline{\text { Jul }}}$ & $\underline{\text { Aug }}$ & Sep & $\underline{\mathrm{Oct}}$ & $\underline{\underline{\text { Nov }}}$ & $\underline{\overline{\text { Dec }}}$ \\
\hline 2009 & $\underline{\underline{J a n}}$ & $\underline{\text { Feb }}$ & Mar & Apr & May & $\underline{\underline{\text { Jun }}}$ & $\underline{\text { Jul }}$ & Aug & $\underline{\text { Sep }}$ & $\underline{\mathrm{Oct}}$ & Nov & $\underline{\underline{\text { Dec }}}$ \\
\hline 2010 & $\underline{\text { Jan }}$ & $\underline{\text { Feb }}$ & Mar & Apr & May & $\underline{\text { Jun }}$ & $\underline{\mathrm{Jul}}$ & Aug & Sep & Oct & Nov & Dec \\
\hline 2011 & $\underline{\mathrm{Jan}}$ & $\underline{\underline{F e b}}$ & Mar & Apr & May & $\underline{\underline{\text { Jun }}}$ & $\underline{\mathrm{Jul}}$ & Aug & Sep & $\underline{\overline{\mathrm{Oct}}}$ & $\underline{\underline{\text { Nov }}}$ & $\underline{\text { Dec }}$ \\
\hline 2012 & $\underline{\mathrm{Jan}}$ & $\underline{\text { Feb }}$ & Mar & Apr & May & Jun & $\underline{\mathrm{Jul}}$ & $\underline{\text { Aug }}$ & $\underline{\text { Sep }}$ & $\underline{\mathrm{Oct}}$ & $\underline{\text { Nov }}$ & $\underline{\mathrm{Dec}}$ \\
\hline 2013 & $\underline{\text { Jan }}$ & Feb & Mar & Apr & May & $\underline{\text { Jun }}$ & $\underline{\mathrm{Jul}}$ & Aug & $\underline{\text { Sep }}$ & $\underline{\mathrm{Oct}}$ & Nov & $\underline{\text { Dec }}$ \\
\hline 2014 & $\underline{\mathrm{Jan}}$ & $\underline{\text { Feb }}$ & Mar & $\underline{\text { Apr }}$ & May & $\underline{\text { Jun }}$ & $\underline{\mathrm{Jul}}$ & Aug & Sep & $\underline{\mathrm{Oct}}$ & $\underline{\mathrm{Nov}}$ & Dec \\
\hline 2015 & $\underline{\underline{J a n}}$ & $\underline{\text { Feb }}$ & Mar & Apr & May & $\underline{\underline{\text { Jun }}}$ & Jul & Aug & Sep & $\underline{\mathrm{Oct}}$ & & \\
\hline
\end{tabular}

Figure 1. The top page of the SOHO/LASCO CME catalog. One row corresponds to all the months in the year. Months not underlined (no link) have no data [10].

$P$ is the energy of proton $=938 \mathrm{Mev}, E$ is the proton kinetic energy [9]. The injection time will be compared with the appearing time from LASCO [7] to ensure the accuracy of the events time and energy.

\section{Applications and Analysis}

\subsection{ERNE/LASCO Analysis}

In this study all selected observations for the peak of solar cycle (24) (2012-2015) have been analyzed. As indicated in paragraph 2, to find the features of solar eruptions by tracking SEP associated with CME for the peak of solar cycle (24) (2012-2015), on this basis the most important events will be analyzed. So for this study 82 event were selected and provided that its speed $(v>1000 \mathrm{~km} / \mathrm{s})$ and of $\left(A W>200^{\circ}\right)$. The analysis of the data related to logarithmic intensity-time profile of proton for resolution time of 1 hour from ERNE for 16 significant event filtered from the 82 event were represented in (Figures 2-7) and this is filtered based on events which have the highest number of CME for each year of the peak of solar cycle (24). By using equations $(1,2,3,4)$ for the adopted events, onset time have been created with the fixed path length method, the flight time of the non-scattered protons along the Archimedean field line of nominal length (1.2 AU) has been calculated so the injection time will be extracted. While the characteristics of the CMEs in C2 for 82 events have been taken from LASCO and analyzed which is shown in Table 1.

\subsection{Statistical Analysis}

The statistical approaches are an important process to detect the correlations among the features phase of the solar cycles. All observations had been analyzed by means of the statistical software (SPSS) program to find out the correlations between speed and acceleration, the distribution of the CPA in degree of the CMEs for the peak 

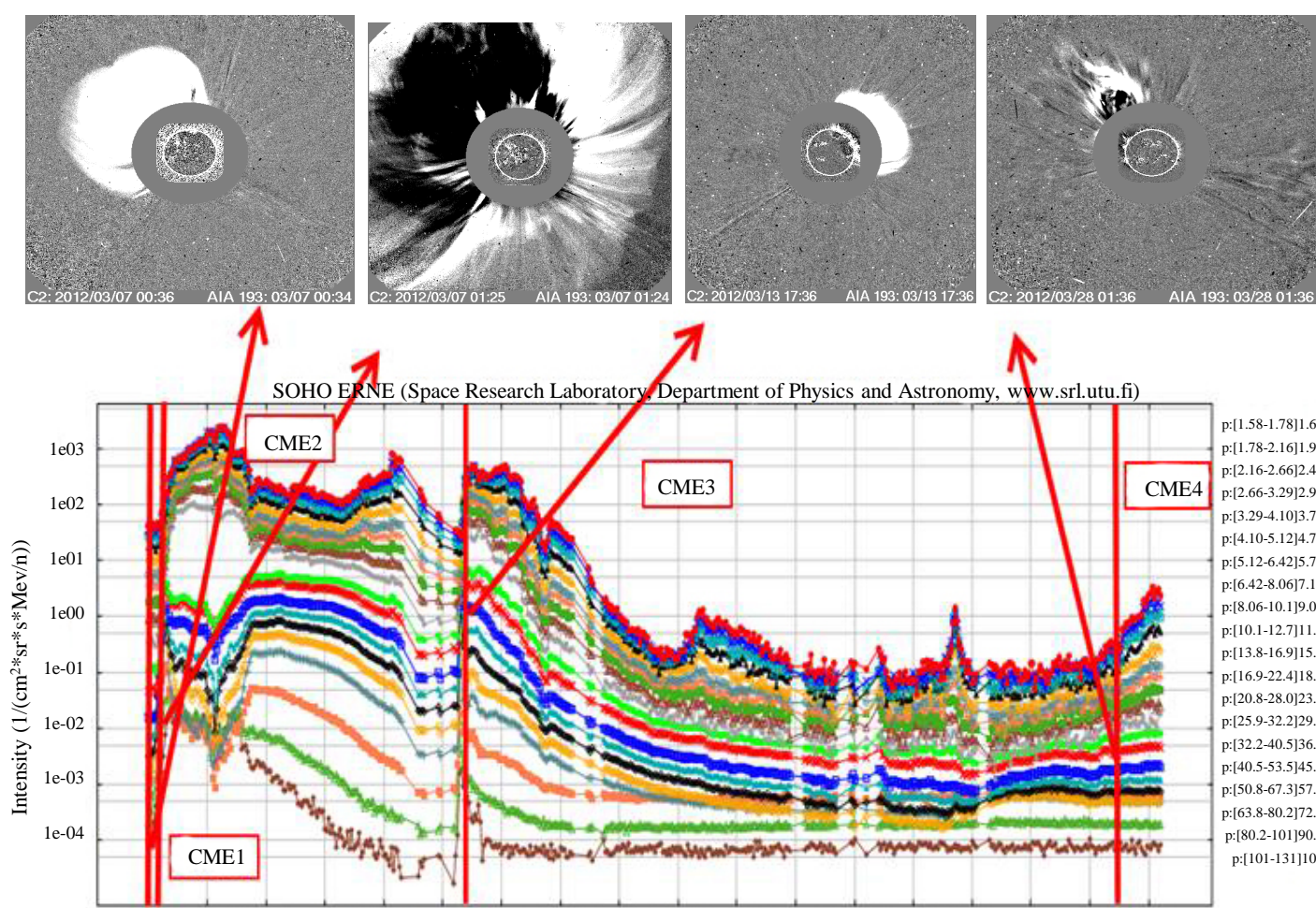

$\mathrm{p}:[1.58-1.78] 1.68$
$\mathrm{p}:[1.78-2.16] 1.97 \times$
$\mathrm{p}:[2.16-2.66] 2.41$
$\mathrm{p}:[2.66-3.29] 2.98$
$\mathrm{p}:[3.29-4.10] 3.70$
$\mathrm{p}:[4.10-5.12] 4.71$
$\mathrm{p}:[5.12-6.42] 5.72$
$\mathrm{p}:[6.42-8.06] 7.15$
$\mathrm{p}:[8.06-10.1] 9.09$
$\mathrm{p}:[10.1-12.7] 11.4$
$\mathrm{p}:[13.8-16.9] 15.4$
$\mathrm{p}:[16.9-22.4] 18.9 \times$
$\mathrm{p}:[20.8-28.0] 23.3$
$\mathrm{p}:[25.9-32.2] 29.1$
$\mathrm{p}:[32.2-40.5] 36.4$
$\mathrm{p}:[40.5-53.5] 45.6$
$\mathrm{p}:[50.8-67.3] 57.4$
$\mathrm{p}:[63.8-80.2] 72.0$
$\mathrm{p}:[80.2-101] 90.5$
$\mathrm{p}:[101-131] 108$

07 00:30 08 07:30 09 14:30 10 20:30 12 03:30 13 09:30 14 16:30 1523:30 17 05:30 18 12:30 19 18:30 21 01:30 22 08:30 23 14:30 24 21:30 26 03:30 27 10:30 28 17:30

March 2012 UT, dd hh:mm (Time resolution: 1hour)

Figure 2. Intensity-time profile of event (7-28) March 2012, the top panel appears the CME1, CME2, CME3 and CME4 (the first C2 appearance), the lower panel appears the intensity time profile from SOHO/ERNE with 1 hour time resolution, all channels.
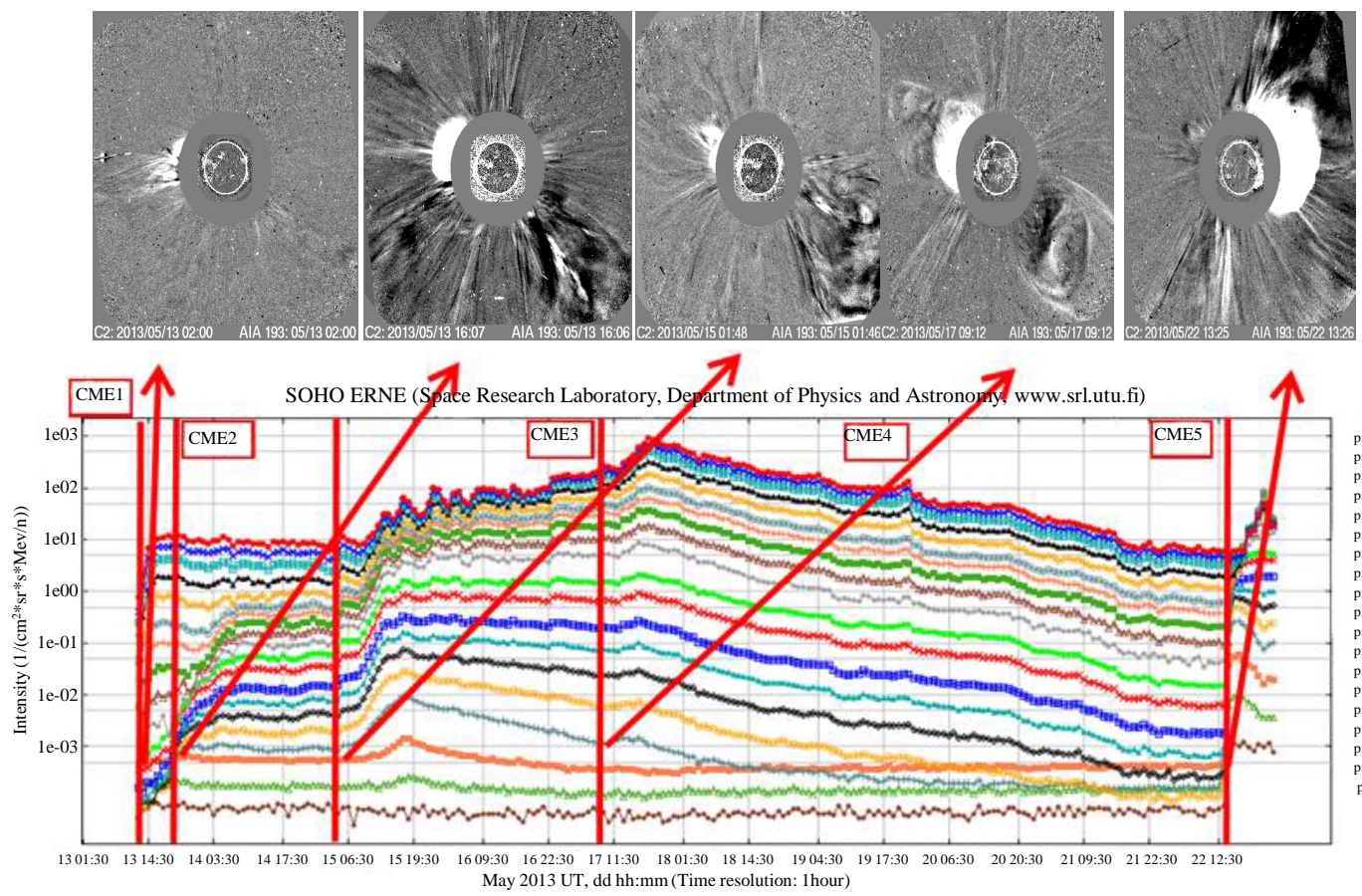

$\mathrm{p}:[1.58-1.78] 1.68$ p: $[2.16-2.6612 .41 \times$ p: $:[2.66-3.2912 .98$. p: $\mathrm{p}:[4.109-5.5 .12] 4.71$ p: $:[5.12-6.42] 5.72=$ p::[8.06-10.1.19.09 8 . p: $[13.8-16.9] 15.4$. :[20.8-28.0]23.3 p:[25.9-32.2]29.1 $\mathrm{p}:[32.2-40.5] 36.4 \circ$ p:[50.8-67.3.357.4 p:[80.2-101]90.5 p: $\mathrm{p}:[101-131] 108$.

Figure 3. Intensity-time profile of events (13-22) May 2013, the top panel appears the CME1, CME2, CME3, CME4 and CME5 (the first C2 appearance), the lower panel appears the intensity time profile from SOHO/ERNE with 1 hour time resolution, all channels. 


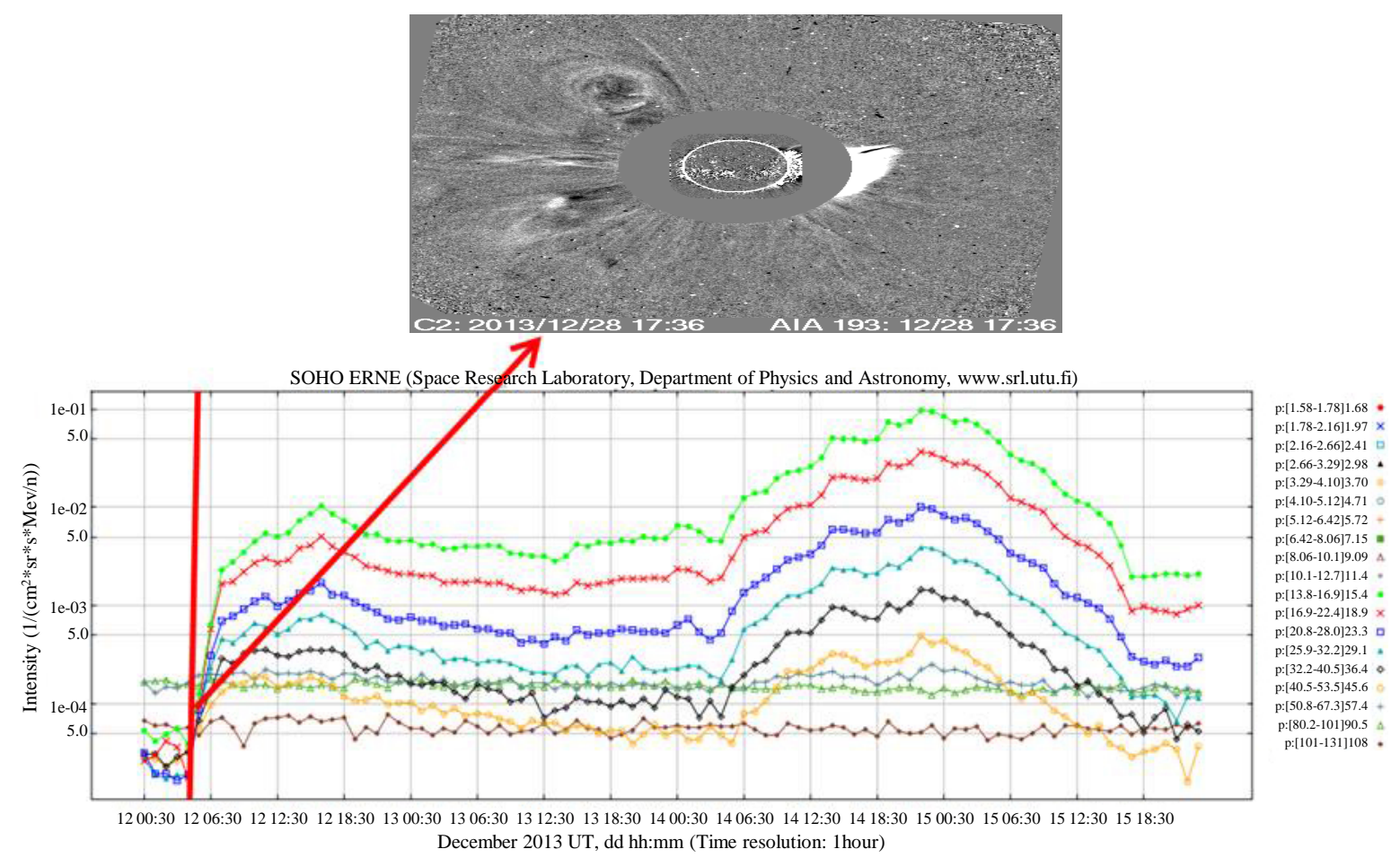

Figure 4. Intensity-time profile of event 12 December 2013, the top panel appears the CME (the first C2 appearance), the lower panel appears the intensity time profile from SOHO/ERNE with 1 hour time resolution, all channels.

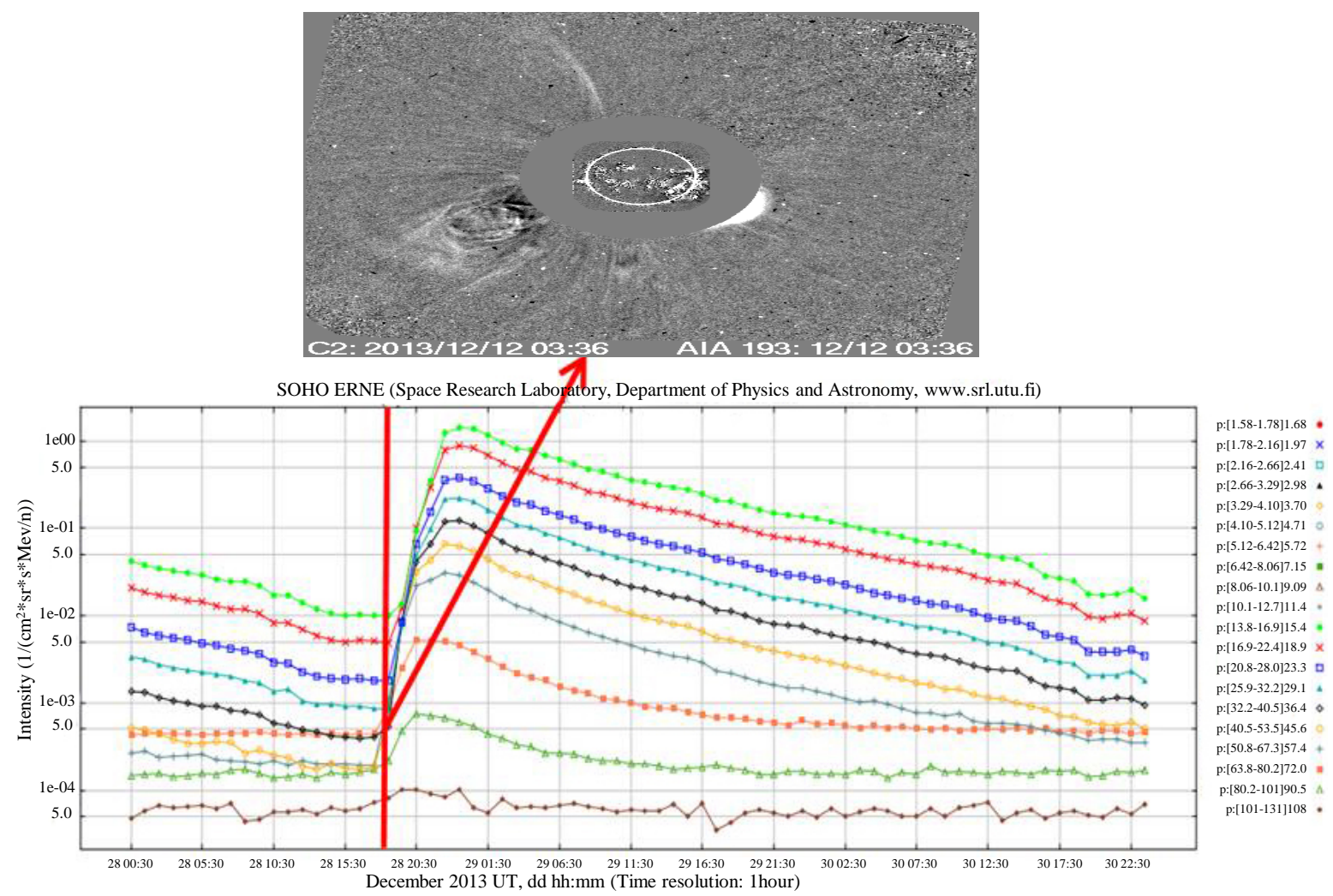

Figure 5. Intensity-time profile of event 28 December 2013, the top panel appears the CME (the first C2 appearance), the lower panel appears the intensity time profile from SOHO/ERNE with 1hour time resolution, all channels. 

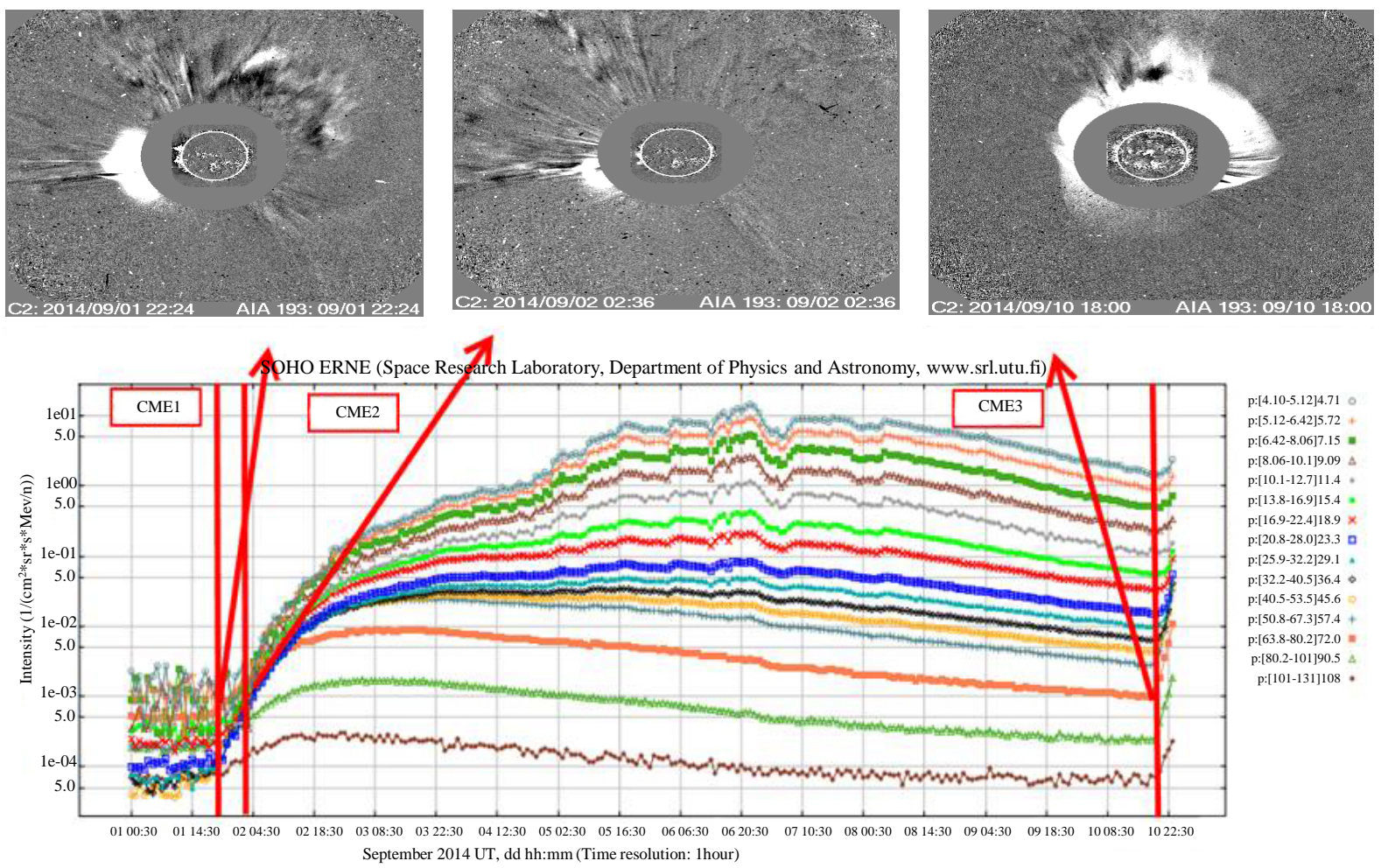

:[4.10-5.12]4.71 。 p:[5.12-6.42]5.72 + p:[6.42-8.06]7.15 = $\mathrm{p}:[8.06-10.1] 9.09 \mathrm{\Delta}$ p:[10.1-12.7]11.4 * $\mathrm{p}:[13.8-16.9] 15.4$. p:[16.9-22.4]18.9 x $\mathrm{p}:[20.8-28.0] 23.3 \mathrm{a}$ p:[25.9-32.2]29.1 * $\mathrm{p}:[32.2-40.5] 36.4$ 。 $\mathrm{p}:[40.5-53.5] 45.6$ ::[50.8-67.3]57.4 + $\mathrm{p}:[80.2-101] 90.5 \Delta$

Figure 6. Intensity-time profile of events (1-10) September 2014, the top panel appears the CME1, CME2 and CME3, (the first C2 appearance), the lower panel appears the intensity time profile from SOHO/ERNE with 1 hour time resolution, all channels.
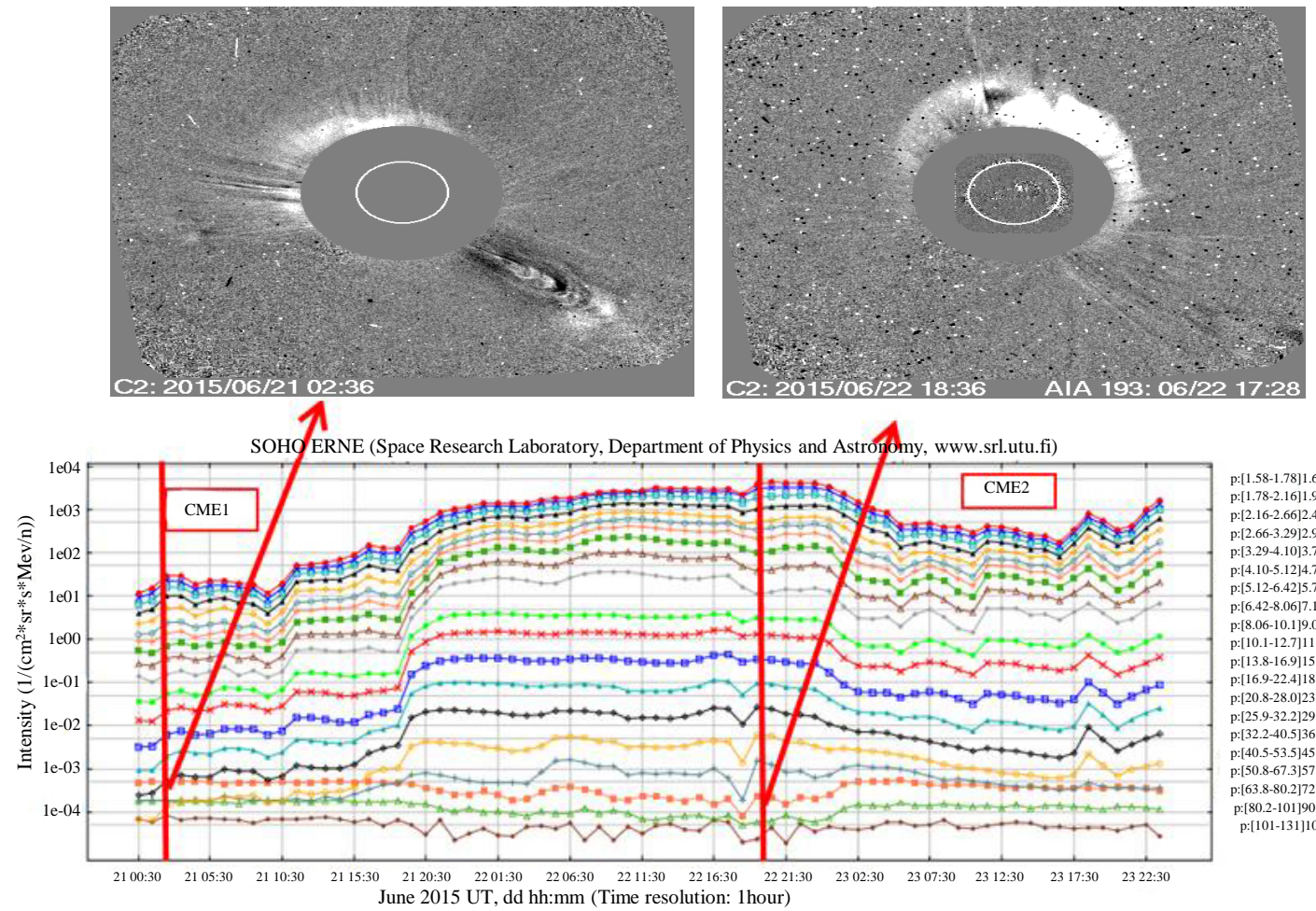

p: $: 1.58-1.7811 .68$ p:[1.78-2.2.161.1.97 $\times$ : $[2.2 .66-3.3 .296] 2.98$, $[3.29-4.1013 .70$ p: $:[4.10-5.12] 4.71$ p:[6.42-8.0667.15 = p:[8.06-10.1]9.09 A $\mathrm{p}:[10.1-12.7] 11.4$ p:[13.8-16.9]15.4 * p:[16.9-22.4]18.9 p: [20.8-28-32.2129.1 p:[25.9-32.2]29.1 ::[40.5-53.5]45.6 p: $\mathrm{p}:[0.5-553.53 .545 .6$. :[63.8-80.2]72.0 " p:[80.2-101] 190.5 p:[101-131]108

Figure 7. Intensity-time profile of events (21-22) June 2015, the top panel appears the CME1 and CME2 (the first C2 appearance), the lower panel appears the intensity time profile from SOHO/ERNE with 1hour time resolution, all channels. 
Table 1. The characteristics of CME of the significant events for the peak of solar cycle (24) (2012-2015).

\begin{tabular}{|c|c|c|c|c|c|c|}
\hline \multirow{2}{*}{$\begin{array}{l}\text { Events } \\
\text { D.M.Y }\end{array}$} & \multicolumn{6}{|c|}{ Characteristics of related CME } \\
\hline & $\begin{array}{l}\text { *First C2App. } \\
\text { (UT) }\end{array}$ & CPA (deg) & AW (deg) & Speed $(\mathrm{km} / \mathrm{s})$ & $\begin{array}{l}\text { Acceleration } \\
\left(\mathrm{m} / \mathrm{sec}^{2}\right)\end{array}$ & $\begin{array}{c}\text { Number of } \\
\text { CME }\end{array}$ \\
\hline (2-27).1.2012 & $15: 12$ & HALO & 360 & 1138 & -8.4 & 6 \\
\hline (4-28).3.2012 & $11: 00$ & HALO & 360 & 1306 & 28.3 & 11 \\
\hline$(17-26) \cdot 5.2012$ & 01:48 & HALO & 360 & 1582 & -51.8 & 2 \\
\hline 23.6.2012 & $07: 24$ & HALO & 360 & 1263 & -29.1 & 1 \\
\hline$(2-23) \cdot 7 \cdot 2012$ & 08:36 & HALO & 360 & 1074 & -26.9 & 4 \\
\hline$(21-31) \cdot 8.2012$ & $20: 24$ & HALO & 360 & 1024 & -39.9 & 2 \\
\hline 20.9.2012 & $15: 12$ & HALO & 360 & 1202 & -54.9 & 1 \\
\hline 23.11.2012 & $23: 24$ & HALO & 360 & 1186 & -13.7 & 1 \\
\hline 6.2 .2013 & $00: 24$ & 4 & 271 & 1867 & -8.2 & 1 \\
\hline (5-15).3.2013 & 03:48 & HALO & 360 & 1361 & 5.1 & 2 \\
\hline$(13-22) \cdot 5 \cdot 2013$ & 02:00 & HALO & 360 & 1270 & 15.9 & 5 \\
\hline 28.6.2013 & 02:00 & HALO & 360 & 1037 & -22.8 & 1 \\
\hline 22.7.2013 & $06: 24$ & HALO & 360 & 1004 & -3.4 & 1 \\
\hline 29.9.2013 & $22: 12$ & HALO & 360 & 1179 & -5.3 & 1 \\
\hline (11-29).10.2013 & $07: 24$ & HALO & 360 & 1200 & -5.5 & 3 \\
\hline (4-7).11.2013 & $05: 12$ & HALO & 360 & 1040 & -40.4 & 3 \\
\hline$(7-31) \cdot 12 \cdot 2013$ & $07: 36$ & HALO & 360 & 5108 & -41.7 & 5 \\
\hline (6-21).1.2014 & 08:00 & HALO & 360 & 1402 & -7.1 & 3 \\
\hline$(22-25) \cdot 2 \cdot 2014$ & $12: 12$ & 247 & 233 & 1023 & 9.5 & 2 \\
\hline 2.4 .2014 & 13:36 & HALO & 360 & 1471 & -1.2 & 1 \\
\hline (9-10).5.2014 & 02:48 & HALO & 360 & 1099 & -19.8 & 2 \\
\hline 8.8.2014 & $16: 36$ & HALO & 360 & 1137 & -28.9 & 1 \\
\hline$(1-26) .9 .2014$ & $11: 12$ & HALO & 360 & 1901 & -240 & 6 \\
\hline (10-19).12.2014 & $18: 00$ & 322 & 228 & 1086 & 34.7 & 3 \\
\hline$(9-21) \cdot 2 \cdot 2015$ & $23: 24$ & HALO & 360 & 1106 & -1.9 & 2 \\
\hline$(7-24) \cdot 3 \cdot 2015$ & $22: 12$ & HALO & 360 & 1261 & -7.3 & 3 \\
\hline 14.4.2015 & 02:36 & HALO & 360 & 1198 & -37.7 & 1 \\
\hline 4.5.2015 & 03:12 & HALO & 360 & 1014 & -25.6 & 1 \\
\hline (9-25).6.2015 & $20: 12$ & 77 & 262 & 1036 & -3.8 & 5 \\
\hline 1.7.2015 & $14: 36$ & HALO & 360 & 1437 & -19.8 & 1 \\
\hline 20.9.2015 & $18: 12$ & HALO & 360 & 1239 & 0.2 & 1 \\
\hline
\end{tabular}

*First C2App: The first appearance time from C2.

of solar cycle (24) (2012-2015), speed and years, acceleration and year as well as the distribution for the number of SEP events as a function of its types for 82 SEP event for the peak of solar cycle (24) (2012-2015). SPSS version 19 Windows based program that can be used to perform data entry and analysis and to create tables and graph and it is capable of handling large amounts of data as well as can perform all of the analyses covered in the text and much more. In order to get clear statistical analysis, 82 peak events of solar cycle (24) (2012-2015) of speed $>1000(\mathrm{~km} / \mathrm{s})$ and angular width $>200^{\circ}$ have been verified.

\section{Discussion}

Figure 2 shows SOHO/ERNE detection for four important clear events especially the particular event on 7 
March 2012, an SEPs event onset at 00:30 UT, 01:30 proton injection time at (00:11, 01:11) UT for proton energies (63.9 - 80.3) Mev, with CPA of Halo type and linear velocity of $(\mathbf{2 6 8 4}, \mathbf{1 8 2 5}) \mathrm{kms}^{-1}$. On 13 March 2012, an SEPs event onset at 17:30UT proton injection time at 16:53 UT for proton energies (20.3 - 28) Mev, with CPA of Halo type and linear velocity of $\mathbf{1 8 8 4} \mathrm{kms}^{-1}$. On 28 March 2012, an SEPs event onset at 01:30UT proton injection time at 12:48 UT for proton energies (16.9 - 22.4) Mev, CPA of Halo and linear velocity of $1033 \mathrm{kms}^{-1}$. Five significant events observed from Figure 3, on 13 May 2013, SEPs event onset at 02:30, 15:30 UT proton injection time at 02:11, 15:11 UT for proton energies (63.9 - 80.3) Mev, CPA of Halo type and linear velocity of $(\mathbf{1 2 7 0}, \mathbf{1 8 5 0}) \mathrm{kms}^{-1}$. On 15 May 2013, SEPs event onset at 01:30 UT proton injection time at 01:11 UT for proton energies (63.9 - 80.3) Mev, CPA of Halo type and linear velocity of $1366 \mathrm{kms}^{-1}$. On 17 May 2013, SEPs event onset at 10:30 UT proton injection time at 10:11 UT for proton energies (50.8 - 67.4) Mev, CPA of Halo and linear velocity of $\mathbf{1 3 4 5} \mathrm{kms}^{-1}$. On 22 May 2013, SEPs event onset at 13:30 UT proton injection time at 13:11 UT for proton energies $(63.9-80.3)$ Mev, CPA of Halo and linear velocity of 1466 $\mathrm{kms}^{-1}$. From Figure 4 on 12 December 2013, SOHO/ERNE detected a SEPs event onset at 03:30 UT proton injection time at 02:56 UT for proton energies (20.8 - 28) Mev, with CPA of $214^{\circ}$ and linear velocity of 1002 $\mathrm{kms}^{-1}$.

From Figure 5 on 28 December 2013, SOHO/ERNE detected a SEPs event onset at 17:30 UT proton injection time at 17:11 UT for proton energies (63.9 - 80.3) Mev, with central position angle (CPA) of Halo, with a linear velocity of $1118 \mathrm{kms}^{-1}$.

Figure 6 shows three events on $(1,2,10)$ September 2014, SOHO/ERNE detected a SEPs events onset at (22:30, 02:30 and 18:30) UT proton injection time at (22:11, 02:11 and 18:11) UT for proton energies (63.9 80.3) Mev, CPA of (Halo, 121 and Halo) and linear velocity of $\left(1404,1141\right.$ and 1267) $\mathrm{kms}^{-1}$.

From Figure 7 on (21-22) June 2015, SOHO/ERNE detected two SEPs events onset at (02:30 and 18:30) UT proton injection time at (02:11 and 18:11) UT for proton energies $(63.9-80.3) \mathrm{Mev}$, with central position angle (CPA) of Halo and linear velocity of (1366 and 1209) $\mathrm{kms}^{-1}$.

Table 1 summarizing the handled observations from LASCO and updating of previous investigations, also exhibit the first appearance, $\mathrm{CPA}$, AW, speed, acceleration and the number of associated $\mathrm{CME}_{\mathrm{s}}$ which is selected for this study ( the peak of solar cycle 24). Table 2 represents onset time and energy for the clear events by the intensity-time profiles obtained from ERNE for the same observations, the injection time, time of flight $\left(T_{f}\right)$ and $\beta$ calculation. While the first appearance time taken from LASCO in order to compare it with onset time for the

Table 2. Represents onset time and energy from ERNE, injection time, flight time $\left(\mathrm{T}_{\mathrm{f}}\right)$ and $\beta$ for the clear events. And the first appearance time of the associated CMEs (peak of solar cycle 24).

\begin{tabular}{ccccccc}
\hline D.Y.M & Energy (Mev) & $\beta$ & $\mathrm{T}_{\mathrm{fmin})}$ & Time onset (UT) & $\begin{array}{c}\text { Time injection } \\
\text { (UT) }\end{array}$ & $\begin{array}{c}\text { First C2App. } \\
\text { (UT) }\end{array}$ \\
\hline 7.3.2012 & 72 & 0.3707 & 26.9 & $00: 30$ & $00: 11$ & $00: 24$ \\
7.3 .2012 & 72 & 0.3707 & 26.9 & $01: 30$ & $01: 11$ & $01: 30$ \\
13.3 .2012 & 23.3 & 0.218 & 45.69 & $17: 30$ & $16: 53$ & $17: 36$ \\
28.3 .2012 & 18.9 & 0.1977 & 50.56 & $01: 30$ & $12: 28$ & $01: 36$ \\
13.5 .2013 & 72 & 0.3707 & 26.9 & $02: 30$ & $02: 11$ & $02: 00$ \\
13.5 .2013 & 72 & 0.3707 & 26.9 & $15: 30$ & $15: 11$ & $16: 07$ \\
15.5 .2013 & 72 & 0.3707 & 26.9 & $01: 30$ & $01: 11$ & $01: 48$ \\
17.5 .2013 & 72 & 0.3707 & 26.9 & $10: 30$ & $10: 11$ & $09: 12$ \\
22.5 .2013 & 72 & 0.3707 & 26.9 & $13: 30$ & $13: 11$ & $13: 25$ \\
12.12 .2013 & 23.3 & 0.218 & 45.69 & $03: 30$ & $02: 56$ & $03: 36$ \\
28.12 .2013 & 72 & 0.3707 & 26.9 & $17: 30$ & $17: 11$ & $17: 36$ \\
1.9 .2014 & 72 & 0.3707 & 26.9 & $22: 30$ & $22: 11$ & $22: 24$ \\
2.9 .2014 & 72 & 0.3707 & 26.9 & $02: 30$ & $02: 11$ & $02: 36$ \\
10.9 .2014 & 72 & 0.3707 & 26.9 & $18: 30$ & $18: 11$ & $18: 00$ \\
21.6 .2015 & 72 & 0.3707 & 26.9 & $02: 30$ & $02: 11$ & $18: 11$ \\
22.6 .2015 & 72 & 0.3707 & 26.9 & $18: 30$ & $02: 36$ \\
\hline
\end{tabular}


promotion of the calculations. From Table 2 we find that the onset time and appearance time are convergent. Figure 8 shows that $90 \%$ of the events was halo $\left(360^{\circ}\right)$ central position angle (CPA), North West $1 \%$, South West 4\%, North East and South East 2\%, and the average speed $1374(\mathrm{~km} / \mathrm{s})$ for the selected observation of this study. Figure 9 shows a scatter plot (using SPSS software vir.19) between the measured acceleration, A (m/ $\left.\mathrm{s}^{2}\right)$ and speed, $\mathrm{v}(\mathrm{km} / \mathrm{s})$ that calculated in Table 1 for the handled observation (82 event) of the CMEs for which the acceleration estimate was possible. Despite the large scatter, acceleration has a probable correlation, where from Table 3 we find the parameter of the regression equation, $B_{\circ}=1347.029$ and $B_{1}=-0.913$, since the principle equation of regression is $\mathrm{Y}=\mathrm{B} \circ \pm \mathrm{B}_{1} \mathrm{X}$ that is mean $(\mathrm{A}=1347.029-0.913 \mathrm{v})$ or $\mathrm{A}=-0.913(\mathrm{v}-1475.388)$. And as shown in Figure 9 and Table 3 that the correlation coefficient is a negative value and its absolute value less than 0.5 (0.122), this shows inverse relationship between speed and acceleration in this region of solar cycle (24) i.e. the peak. So the CMEs $(\mathrm{v}<1475.388 \mathrm{~km} / \mathrm{s})$ accelerate, and CMEs $(\mathrm{v} \sim 1475.388 \mathrm{~km} / \mathrm{s})$ have no realized acceleration and for CMEs $(\mathrm{v}>1475.388 \mathrm{~km} / \mathrm{s})$ decelerate. Close to the Sun " $\mathrm{A}$ " is determined by the driving force and if $\mathrm{A}=0$ then $\mathrm{v}=1475.388 \mathrm{~km} / \mathrm{s}$. From Figure 10 we note that the "Average" and "Median" almost

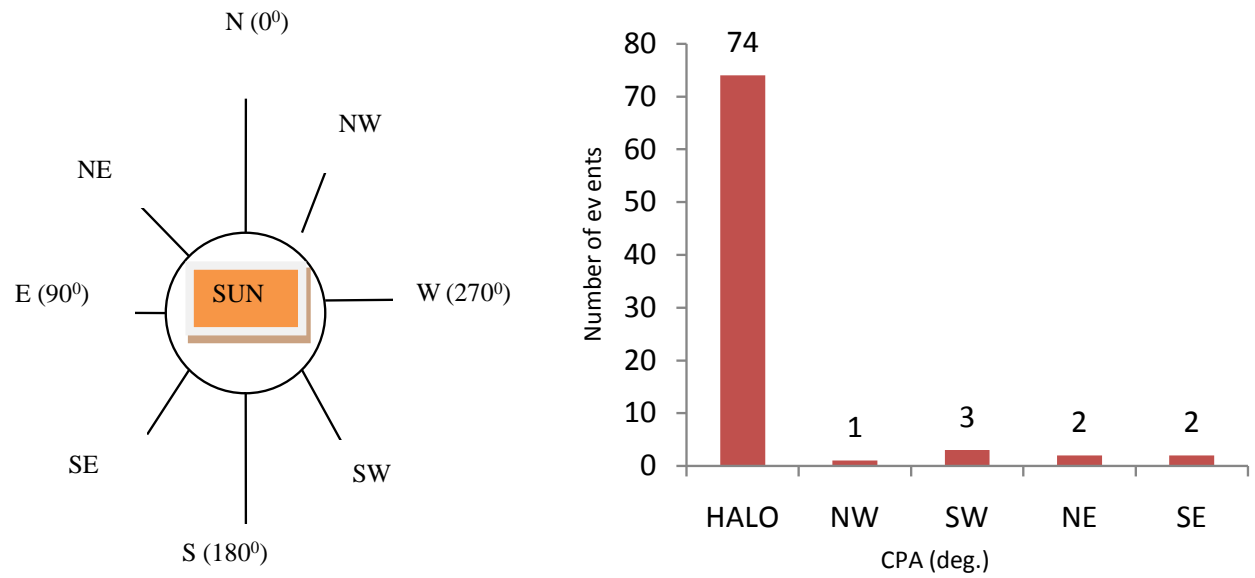

Figure 8. The distribution of the Central Position Angle (CPA) (deg.) of the CMEs for the peak of solar cycle (24) (2012-2015).

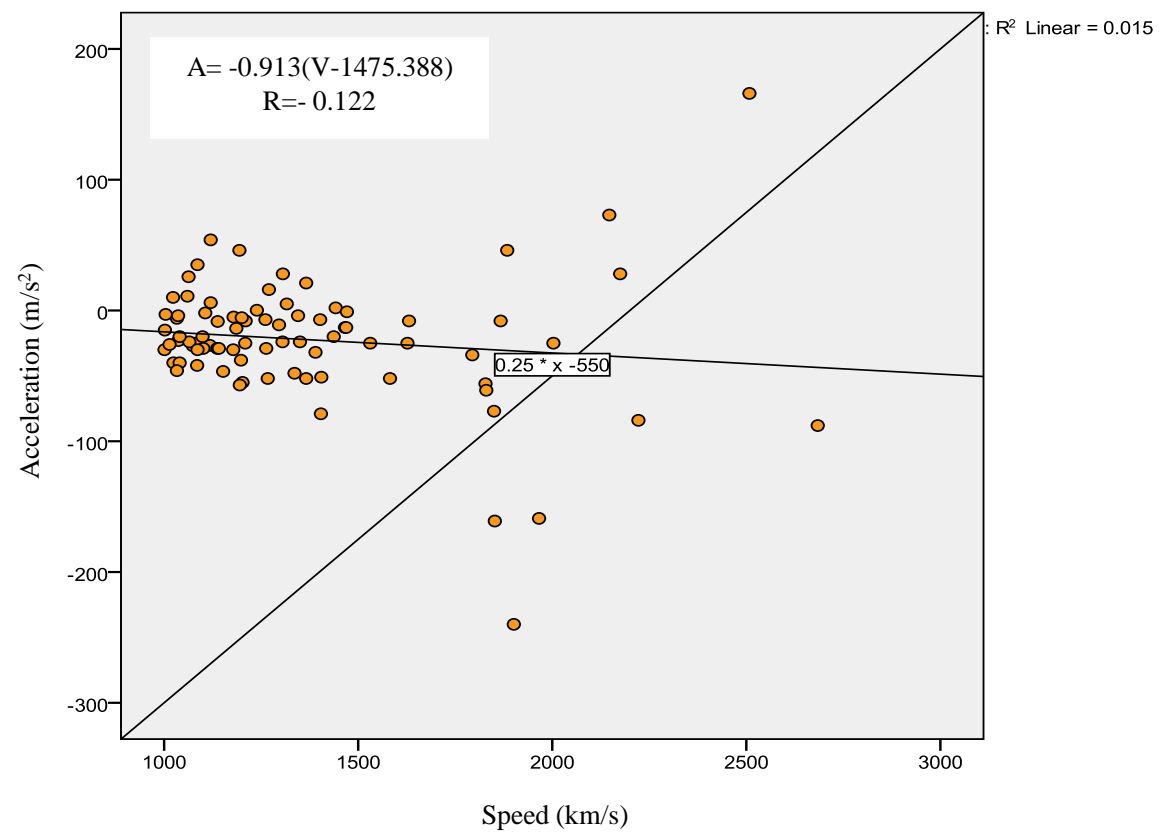

Figure 9. Scatter plot between the acceleration $\left(\mathrm{m} / \mathrm{s}^{2}\right)$ and speed $(\mathrm{km} / \mathrm{s})$ of 82 events for the peak of solar cycle (24) (2012-2015), " $\mathrm{R}$ ” is the correlation coefficient of the distribution. 
Table 3. Model Summary of the relation between acceleration and speed from (2012-2015).

\begin{tabular}{cccc}
\hline Model & $\mathrm{R}$ & R Square & Adjusted R Square \\
\hline 1 & $-0.122^{\mathrm{a}}$ & 0.015 & 0.002 \\
\hline
\end{tabular}

a. Predictors: (Constant), Acceleration.

\begin{tabular}{ccccc}
\hline Model & \multicolumn{2}{c}{ Unstandardized Coefficients } & Standardized Coefficients & \multirow{2}{*}{ Sig. } \\
\cline { 2 - 4 } 1 & $\mathrm{~B}$ & Std. Error & Beta & 0.0000 \\
(Constant) & 1347.029 & 44.678 & & 0.277 \\
\hline Acceleration & -0.913 & 0.834 & -0.122 & 0.22 \\
\hline
\end{tabular}

b. Dependent Variable: SPEED.

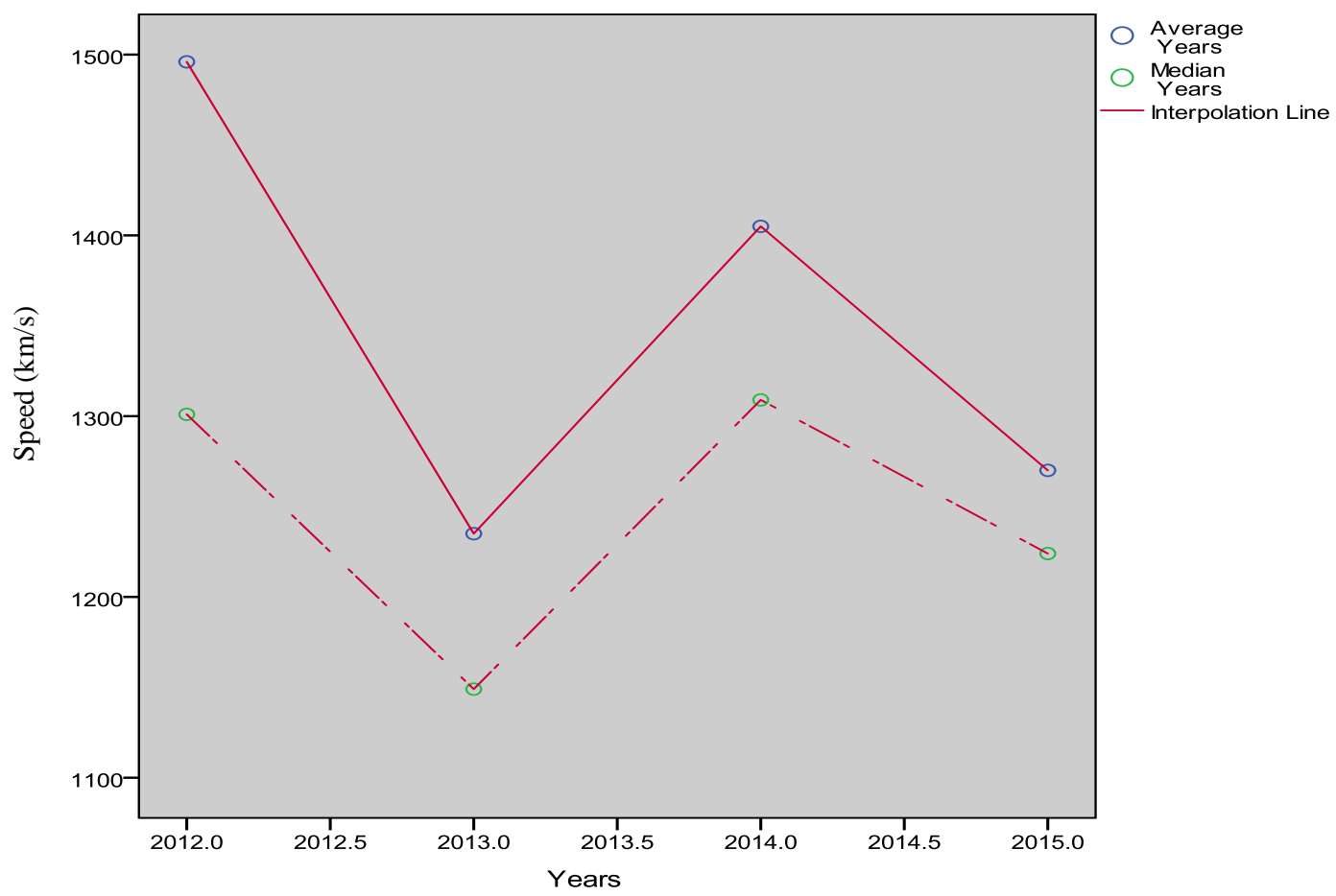

Figure 10. Average and median of CMEs speed (km/s) for the peak of solar cycle (24) (2012-2015).

compatible and statistically this refers to accurate chose of the observations for the peak of solar cycle (24), and also from Figure 10 we note the existence of two peaks for the speed, the first peak in the year 2012 and the other in the year 2014, this corresponds that solar cycle (24) have double peaks [11], as well as the behavior of the curves in Figure 10 and Figure 11 verified the approaches of Figure 9, that acceleration inversely proportional to the speed as mentioned before. From Figure 12 we note that 39\% of total events are gradual and 29\% are impulsive, the remaining is $32 \%$ are not clear events.

\section{Summary}

In this study the data analysis of the present work leads us to conclude the following:

1) The number of events for the peak of solar cycle (24) (2012-2015) which verifies the required conditions was 82 event, and this was from SOHO/LASCO CME Catalog [7] and ERNE.

2) The filtered events from 82 events as described in paragraph 2, were 16 events for the peak of solar cycle (24) which were verified by ERNE from the logarithmic intensity-time profile of these events.

3) It turns out that from these 82 events, $90 \%$ of the events were halo $\left(360^{\circ}\right)$ central position angle (CPA), North West 1\%, South West 4\%, North East and South East 2\%, as well as for associated SEP found that 39\% 


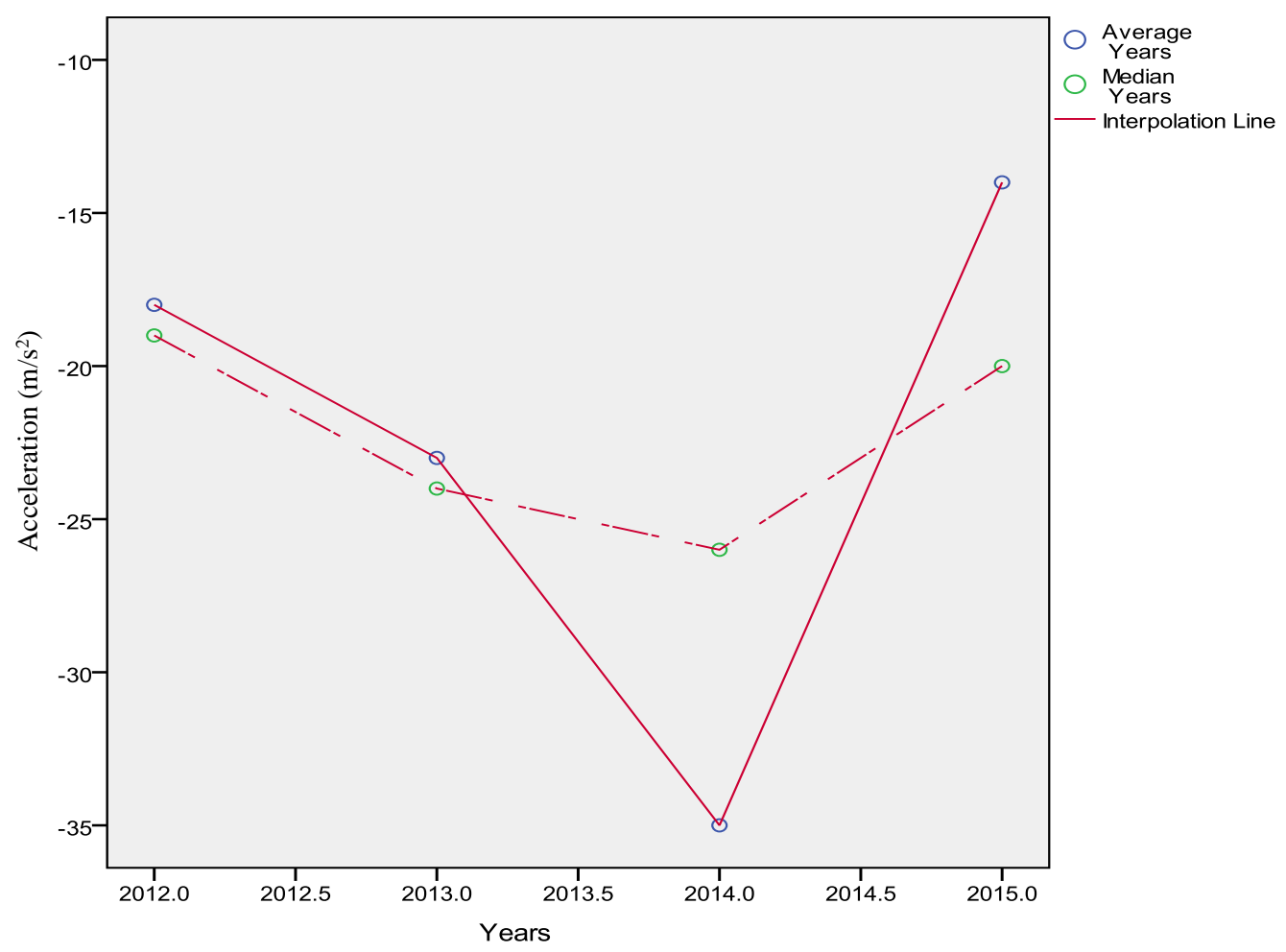

Figure 11. Average and median of CMEs acceleration $\left(\mathrm{m} / \mathrm{s}^{2}\right)$ for the peak of solar cycle (24) (20122015) for 82 events.

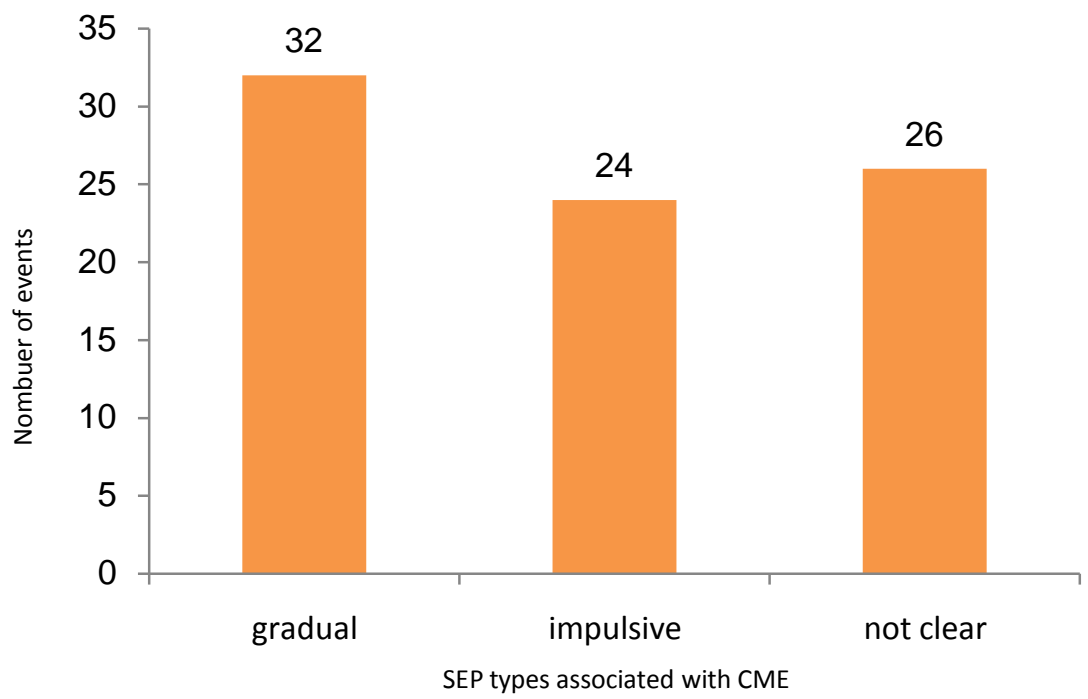

Figure 12. Histogram distribution for the number of events as a function of its type for 82 events for the peak of solar cycle (24) (2012-2015).

of gradual events and $29 \%$ of impulsive events while $32 \%$ were not clear events.

4) All results obtained in (Table 1 and Table 2) and (Figures 2-7) were hired for the purpose of statistical characteristics of SEP solar events for the peak of solar cycle (24), and we note that the onset time and appearance time almost identical and this shows the accuracy of analysis.

5) The results of injection time show that the bulk of the particle acceleration occurs during the impulsive phase of the events near the Sun. 
6) The logarithmic intensity-time profile of gradual SEP shows events of temporal and spatial behavior depending on factors such as spacecraft position with respect to the CME.

7) From statistical analysis of speed and acceleration of 82 events for the whole peak of solar cycle (24) we found that the acceleration inversely proportional to speed and the relationship between them is not relevant, because the absolute value of the correlation coefficient between acceleration and speed is less than 0.5 ( $\mathrm{R}=$ $-0.122)$. So the CMEs $(\mathrm{v}<1475.388 \mathrm{~km} / \mathrm{s})$ accelerate, and CMEs $(\mathrm{v} \sim 1475.388 \mathrm{~km} / \mathrm{s})$ have no realized acceleration and for CMEs ( $>1475.388 \mathrm{~km} / \mathrm{s})$ decelerate.

8) We note that the speed increases in two region in the year 2012 and in the year 2014 and this is confirmed by the convergence of median and average, and this confirms that the peak of solar cycle (24) really is double peak [12] [13]. And to make sure of this fact, a simple test was held for the relationship between the solar events SEPs and the number of sun spot for the peak of solar cycle (24) (2012-2015) (sun spot number is an indicator of solar cycle) by considering the value of the correlation coefficient " $\mathrm{R}$ " through SPSS statistical program, so the result of $\mathrm{R}=0.815$, and according to statistical measurements for correlation coefficients, this result indicates to a relevant relation between solar events and solar cycle peak.

In fact, all these applications and approaches accounted for database work of the space agencies, in order to forecast the solar wind and warning from it, because some of solar wind affects Earth's atmosphere and influence, satellites, power grids, communications, etc...and some other pass to other planets.

\section{References}

[1] Lang, K. (2009) The Sun from Space. Springer-Verlag, Berlin Heidelberg, 1-251.

[2] Kallenrode, M.B. (2003) Current Views on Impulsive and Gradual Solar Energetic Particle Events. Journal of Physics G: Nuclear and Particle Physics, 29, 965-981. PII: S0954-3899(03)53935-4.

[3] Gopalswamy, N., Yashiro, S., Michalek, G., Stenborg, G., Vourlidas, A., Freeland, S. and Howard, R. (2009) The SOHO/LASCO CME Catalog. Earth Moon and Planets, 104, 295-313. http://dx.doi.org/10.1007/s11038-008-9282-7

[4] http://cdaw.gsfc.nasa.gov/CME_list/

[5] Al-Sawad, A. (2009) Multi Eruption Solar Energetic Particle Events Observed by SOHO/ERNE. Ph.D Thesis, Turku University, Turku, Finland.

[6] http://www.srl.utu.fi/erne_data/

[7] Lacoste, H. and Ouwehand, L., Eds. (2006) Modulation of Velocity Dispersion of Solar Energetic Particles by Pre-Event Background. 7-12 May 2006, Girardini Naxos, ESA SP-617, European Space Agency, Published on CDROM, 131-1.

[8] Torsti, J., Kocharov, L., Teittinen, M., Anttila, A., Laitinen, L., Mkel, P., Riihonen, E., Vainio, R. and Valtonen, E. (1999) Energetic ( 10 - $65 \mathrm{MeV}$ ) Protons Observed by ERNE on August 13-14, 1996: Eruption on the Solar Back Side as a Possible Source of the Event. Journal of Geophysical Research, 104, 9903-9909. http://dx.doi.org/10.1029/1998JA900017

[9] Huttunen-Heikinmaa, K., Valtonen, E. and Laitinen, T. (2005) Proton and Helium Release Events Observed with SOHO/ERNE. Astronomy and Astrophysics, 442, 673-685.

[10] http://vso.nascom.nasa.gov/cgi-bin/vso/catalog.pl

[11] Shepherd, S.J., Zharkov, S.I. and Zahrkova, V.V. (2014) Prediction of Solar Activity from Solar Background Magnetic Field Variation in Cycle 21-23. Astrophysical Journal, 795, 1-8.

[12] Lockwood, M., Owens, M., Barnard, L., Davis, C. and Thomas, S. (2012) Solar Cycle 24: What Is the Sun up to? Astronomy \& Geophysics, 53, 9-15.

[13] Hathaway, D., Wilson, R. and Reichmann, E. (1994) The Shape of Sunspot Cycle. Solar Physics, 151, 177-190. http://dx.doi.org/10.1007/BF00654090 


\section{Submit or recommend next manuscript to SCIRP and we will provide best service for you:}

Accepting pre-submission inquiries through Email, Facebook, LinkedIn, Twitter, etc.

A wide selection of journals (inclusive of 9 subjects, more than 200 journals)

Providing 24-hour high-quality service

User-friendly online submission system

Fair and swift peer-review system

Efficient typesetting and proofreading procedure

Display of the result of downloads and visits, as well as the number of cited articles

Maximum dissemination of your research work

Submit your manuscript at: http://papersubmission.scirp.org/ 